\title{
PERIPHERAL OLIGOARTRITE OPENING CASE OF VASCULITIS ASSOCIATED WITH MULTIBACILAR HANSENIASIS - CASE REPORT
}

Diogo Cunha Lacerda (FAG, Cascavel, PR, Brasil), Brunno Mehret Moleta (FAG, Cascavel, PR, Brasil), Rodrigo Zuber Maciel (FAG, Cascavel, PR, Brasil), Rafaela Sorpile Araujo (FAG, Cascavel, PR, Brasil), Leandro Silva Pivato (FAG, Cascavel, PR, Brasil), Marina Peremida (FAG, Cascavel, PR, Brasil), Lucas Androczevcz Silva (FAG, Cascavel, PR, Brasil), Leonardo Michaelis Schmidt (FAG, Cascavel, PR, Brasil), Maurício Piekala (FAG, Cascavel, PR, Brasil)

\section{BACKGROUND}

Vasculitis is an inflammatory disease of blood vessels, which has the walls invaded by immune cells, causing stenosis, occlusion, formation of aneurysms and/or hemorrhages. The disease is suspected in patients with fever of unknown etiology, fatigue, joint pain, thromboembolic disease and/or multiple mononeuritis. Leprosy is a chronic, granulomatous, involvement of multiple organs, having as etiological agent the Mycobacterium leprae.

\section{CASE REPORT}

A 43-year-old male, electrician, started a peripheral oligoarthritis in the knees, right wrist and left ankle at 6 months of evolution, associated with worsening of physical efforts and morning stiffness less than one hour. Initiated treatment with prednisone low dose, AINE and methotrexate. Three months later, joint pain worsened, decreased strength to left foot dorsiflexion and $6 \mathrm{~kg}$ loss. Hemogram, creatinine, calcium, rheumatoid factor, TSH was normal and HLAB27 negative. Previous medications were maintained, increased dose of prednisone to $20 \mathrm{mg} /$ day and methotrexate $20 \mathrm{mg}$ once a week. Two months later, the pacient returned with reduced arthritis and partial improvement in the mobilization of the left foot. Electroneuromyography of legs evidenced axonal sensory neuropathy bilateral of superficial fibular nerves, and motor neuropathy of the left fibular nerve, atthe knee region, compatible with multiple neuropathy compatible whit Vasculit. Prescribed azathioprine $100 \mathrm{mg} /$ day and dose of methotrexate was increased to $25 \mathrm{mg} /$ week, as the prednisone to $1 \mathrm{mg} / \mathrm{kg} /$ day. 6 months later, the pacient progressed with weakness, tingling in the right leg and worsering of left foot dorsiflexion. New electromyography did not show signs of vasculitis. Due to neurological worsening and absence of inflammatory signs, the hypothesis of leprosy was raised, referring the patient to the Dermatologist. Witch closed the diagnosis of multibacillary pure neural leprosy with presence of thickening palpation bilateral common fibular nerve and right posterior tibial nerve, even BAAR and lymph negative and without cutaneous lesions. Initiating treatment with polychemotherapy, suspending other medications.

\section{CONCLUSION}

The report refers to a chronic peripheral oligoarthritis, evolving with a multiple left-sided mononeuritis, compatible with vasculitis, in wich the patient had partial response to treatment. Due to neurological worsening in the lower limbs and nonresponse to immunosuppressive treatment, he was referred to the dermatologist, even with BAAR and lymph negative and without cutaneous lesion, closed the diagnosis of pure neural multibacillary leprosy. This case shows how leprosy can mimic inflammatory and/or autoimmune diseases. 